\title{
A Review and a Limited Comparison of Methods for Measuring Total Volatile Organic Compounds in Indoor Air
}

\author{
A.T. Hodgson \\ Lawrence Berkeley Laboratory \\ Energy and Environment Division \\ University of California \\ Berkeley, CA 94720
}

April 1995

This project was supported by the Assistant Secretary for Energy Efficiency and Renewable Energy, Office of Building Technologies, Building Systems and Materials Division of the U.S. Department of Energy under Contract DE-AC03-76SF00098. 


\section{SCLAI MER}

This document was prepared as an account of work sponsored by the United States Government. While this document is believed to contain correct information, neither the United States Government nor any agency thereof, nor the Regents of the University of California, nor any of their employees, makes any warranty, express or implied, or assumes any legal responsibility for the accuracy, completeness, or usefulness of any information, apparatus, product, or process disclosed, or represents that its use would not infringe privately owned rights. Reference herein to any specific commercial product, process, or service by its trade name, trademark, manufacturer, or otherwise, does not necessarily constitute or imply its endorsement, recommendation, or favoring by the United States Government or any agency thereof, or the Regents of the University of California. The views and opinions of authors expressed herein do not necessarily state or reflect those of the United States Government or any agency thereof or the Regents of the University of California. 


\title{
A Review and a Limited Comparison of Methods for Measuring
}

\section{Total Volatile Organic Compounds in Indoor Air}

\author{
A.T. Hodgson \\ Lawrence Berkeley Laboratory \\ Energy and Environment Division \\ University of California \\ Berkeley, CA 94720
}

\begin{abstract}
A number of methods attempt to measure the combined concentrations of volatile organic compounds (VOCs) in indoor air as total VOCs (TVOC). This paper reviews TVOC methods recently presented in the literature and in an international conference on indoor air quality for the purposes of identifying common practices and of assessing the impacts that choices of sample collection media and analytical methods and instrumentation can have on TVOC results.
\end{abstract}

The paper also presents the results of laboratory and field comparisons of three TVOC methods. These are a flame-ionization-detector (FID) method, a gas chromatography/mass spectrometry (GC/MS) method, and a method employing a photoacoustic infra-red (IR) gas monitor. The laboratory experiments were conducted with eight different mixtures of VOCs. The FID method demonstrated an average accuracy of $93 \pm 18$ percent when the measured values were calculated as concentrations of carbon. The FID and GC/MS methods demonstrated average accuracies of $75 \pm 22$ and $77 \pm 37$ percent, respectively, when the measured hydrocarbon-equivalent values were compared to the expected mass concentrations of the mixtures. The higher uncertainty for the FID was largely due to the low mass response of 27 percent for chlorinated compounds. The response of the IR gas monitor varied between 6 and 560 percent for different classes of compounds. Air samples from ten buildings were analyzed by both the FID and GC/MS methods. The results were highly correlated and similar, with the GC/MS values approximately 20 percent higher on average.

Key Words: Total volatile organic compounds, TVOC, volatile organic compounds, VOCs, flameionization detection, GC/MS, infra-red gas monitor.

\section{Introduction}

There is a strong interest in the quantification of volatile organic compounds (VOCs) as a measure of indoor air quality. One reason for this interest is the belief that VOCs may contribute to a complex of sub-chronic health symptoms referred to as sick building syndrome (Mølhave and Nielsen, 1992; M. Hodgson et al., 1994). Typically, VOCs occur in buildings as mixtures of many different compounds encompassing a number of chemical classes and spanning broad ranges of volatility, molecular weight and size. Researchers have tried to characterize these mixtures by several methods. The simplest methods attempt to measure the combined concentrations of individual compounds as total VOCs (TVOC).

The World Health Organization (WHO) defines VOCs as organic compounds sampled by adsorption on a solid sorbent with a lower boiling point limit between 50 and $100^{\circ} \mathrm{C}$ and an upper limit between 240 and $260^{\circ} \mathrm{C}$ (WHO, 1989). An elementary definition of TVOC is , therefore, the sum of the air concentrations of these individual VOCs. Mølhave and Nielsen (1992) discuss the requirements for an ideal TVOC method. In practice, the measurements are made using a variety of readily available instrumentation and methods whose details operationally define TVOC. This 
results in a general lack of consistency among TVOC measurements as noted in a review of concentrations of VOCs in indoor air (Brown et al., 1994).

This paper first reviews the recent literature on the measurement of TVOC with an emphasis on the methods reported at Indoor Air '93, The Sixth International Conference on Indoor Air Quality and Climate, Helsinki, Finland, June, 1993. This conference was comprehensive and is probably representative of current practices in indoor air research in Europe and North America. The purpose of the review is to identify common practices and to elucidate the implications that choices of sample collection media and analytical methods and instrumentation can have with respect to the results that are obtained. The paper concludes with the presentation of laboratory and field evaluations of three different TVOC methods.

\section{Review of TVOC Methods}

There are at least 30 papers in the Proceedings of Indoor Air ' 93 which describe in various detail TVOC methods or which used TVOC measurements in their studies. The objectives of these studies varied widely. Many were field studies to characterize indoor air quality or to identify sources of VOCs; others were laboratory studies of emissions of VOCs from products and materials; still others dealt more directly with relationships between VOCs and health symptoms.

The methods described in Indoor Air '93 are broadly categorized in Table 1 by the sampling method, the sample collection media, the analytical instrumentation and the compound(s) used as a calibration standard or reference.

\section{Sampling Considerations}

For the majority of the methods in Indoor Air '93, samples of VOCs were collected in the field (or from a chamber) by various techniques and returned to a laboratory for analysis. Both diffusive and active sampling methods were used, although the preponderance of the methods used active sampling.

Diffusive sampling often employs activated carbon-based samplers. Shields and Weschler (1987) reported an average diffusive sampling rate for 40 compounds collected on a commercial organic vapor monitor of $23 \mathrm{~cm}^{3} \mathrm{~min}^{-1}$ with a relative standard deviation or coefficient of variation (CV) of 25 percent. This low rate necessitates relatively long sampling intervals (days to several weeks) as the components are recovered by solvent extraction which significantly dilutes the sample. If sampling intervals are too short, only the most abundant compounds will be above limits of detection, and significant sample mass may be overlooked. Sorbents that can be thermally desorbed, such as Tenax and Carbotrap, have also been used for passive sampling (e.g., De Bortoli et al., 1989). These avoid the problem of solvent dilution.

As shown in Table 1, Tenax is the most commonly used sampling media for active sampling. Sample volumes typically range from several to approximately $15 \mathrm{~L}$ collected over a few minutes to hours. Sample components are recovered by thermal desorption. Tenax has the advantage of being thermally stable with relatively low blank and artifact levels. In addition, there is a large body of historical VOC data that has been obtained using Tenax. Because of its moderate surface area, Tenax is only partially retentive of very volatile compounds with boiling points of 50 to $100^{\circ} \mathrm{C}$ and below. This limit is the practical basis for the WHO distinction between very volatile and volatile compounds.

Other sorbent systems are also used with thermal desorption recovery of the sample components. These may utilize carbonaceous materials such as Carbotrap or multiple layers of sorbents. Such multi-sorbent samplers contain sorbents with different surface areas. They are designed to extend the sampling range to quantitatively include many very volatile compounds. The most volatile components are trapped by the higher surface area materials near the exit end 
of the sampler, and the least-volatile and most difficult to recover compounds are trapped near the inlet end on a lower surface area material, such as Tenax. For thermal desorption recovery, the gas flow is reversed through the sampler so that high-boiling compounds do not come in contact with high surface area sorbents. Breakthrough volumes for a number of representative very volatile compounds collected on a multi-sorbent sampler were found to be in excess of typical sample volumes (Hodgson and Girman, 1989).

Tubes containing activated carbon, originally intended for industrial hygiene applications, are still popular for VOC sampling in indoor air. Six papers in Indoor Air '93 utilized such a device. Sample components are recovered from the carbon by extraction with a low-boiling solvent such as carbon disulfide. Because the sample is solvent extracted, it is significantly diluted by a factor of $100-1,000$. This means that a very large volume sample (perhaps as large as $1 \mathrm{~m}^{3}$ depending upon the method) must be collected to achieve the same sensitivity for individual compounds as for a thermally-desorbed sampler. If the sample size is too small, many less abundant compounds, which together may account for a large fraction of the mass in a sample, may be overlooked. In addition, there may be breakthrough losses of the most volatile components during extended high-volume sampling, and evaporative losses of these compounds can occur during extraction. The advantage of the method is that it only requires commonly available GC instrumentation for analysis.

Whole air samples can be actively collected using passivated stainless-steel canisters or gas-sampling bags; however, none of the papers on TVOC in Indoor Air ' 93 described or utilized this method. Canisters are preferred over gas-sampling bags because they can be rigorously cleaned to produce acceptably low blank concentrations. With canisters, a gas dryer is often used to remove water from the sample during the sample concentration procedure. This results in at least partial loss of the more hydrophilic compounds and is one reason why the canister method is typically only used for the determination of specific target compounds. The drying step can be eliminated by using a highly sensitive detector to analyze sufficiently small air volumes so that water does not interfere in the analysis.

\section{Analytical Considerations}

Three papers described direct on-site analysis techniques for the measurement of TVOC. The techniques used a flame-ionization detector (FID) and a photoacoustic infrared (IR) detector. Photoionization detection (PID) is another similar on-site technique. These techniques typically do not employ a chromatographic column for separation of compounds. Instead, air is pumped directly through a detection cell, and a continuous real-time signal is produced which is used as a measure of TVOC. In one application, an FID instrument was effectively used to make near continuous measurements of TVOC in two office buildings over a period of several months (Batterman and Peng, 1995). However, an FID instrument requires hydrogen gas for operation and, therefore, is generally not well suited for surveys in occupied buildings. With the photoacoustic IR, a broad band filter is used to detect hydrocarbons as a group. The sensitivity of the response can, however, vary over more than an order of magnitude for different classes of organic compounds. PID instruments suffer from a similar problem of variable sensitivity, as VOCs are ionized at different energies. For example, a PID is approximately an order of magnitude more sensitive to aromatic hydrocarbons than it is to aliphatic hydrocarbons. Since the compositions of VOCs in air in buildings vary considerably, photoacoustic IR and PID on-site techniques are generally not useful for inter-building comparisons of TVOC concentrations.

Two analytical methods are predominantly used for the laboratory measurement of TVOC in solvent- or thermally-recovered sample extracts. Sixteen papers in Indoor Air ' 93 described methods that employed a gas chromatograph (GC) with a FID; seven papers described GC methods in which a mass spectrometer (MS) was used as the detector. Column selection, as well as $\mathrm{GC}$ oven conditions, will affect the classes and the volatility range of the compounds that are included in the analysis. In many cases, the sample components were resolved on multipurpose, 
(1-5\%-phenyl)methyl-polysiloxane, capillary columns which are appropriate for a broad range of primarily non polar compounds.

One FID method for TVOC in indoor air which does not require chromatographic separation of individual compounds has been reported (Hodgson et al., 1991). Samples were collected on multi-sorbent samplers and recovered by thermal desorption. During the sample concentration step, a small portion of the sample was split off and analyzed directly by an FID. The FID produced a single peak that encompassed a volatility range approximately delimited by 2methylbutane and $n$-hexadecane. A mixture of alkane hydrocarbons was used for calibration.

Although an FID is considered to be a universal detector, its response is strongly dependent upon compound structures and the presence of functional groups and heteroatoms. Yieru et al. (1990) investigated the FID responses for a group of 56 hydrocarbons, chlorinated hydrocarbons, oxidized compounds and nitrogen-containing compounds. Relative to decene, the mean response factor based on compound mass was 0.59 with a CV of 49 percent. Bromine and chlorine containing compounds had the lowest relative responses, in some cases less than 0.2 . However, when the data were converted to responses relative to carbon $\left(R_{R} F_{C}\right)$, they were highly uniform with a mean response of 0.98 and a CV of only eight percent. Oxidized compounds generally had the lowest carbon responses. Good carbon regularity for $\mathrm{RRF}_{\mathrm{C}}$ is consistent with the postulated mechanisms of the flame-ionization process. Thus, while an FID may not accurately quantify the mass of halogenated or oxidized compounds, its response to carbon is only moderately affected by the presence of heteroatoms.

Eight of the FID methods presented at Indoor Air '93 used toluene as the reference compound. Another eight used a single alkane hydrocarbon (hexane through decane) or a mixture of compounds. Because of the good regularity of an FID's carbon response, the choice of a specific hydrocarbon standard is not overly critical. In addition, differences among responses for hydrocarbons are minimized if an FID is calibrated as carbon mass, although this is not generally done. A carbon value can easily be transformed to an equivalent mass of toluene or hexane, for example. In addition, a concentration expressed as ppb carbon is readily converted to the molar volume concentration of a standard compound by dividing by the appropriate carbon number.

When analyzing TVOC by GC/MS, the instrument should be scanned over the entire mass range of the sample to obtain a total-ion-current (TIC) chromatogram. The TIC of the sample can then be integrated and calibrated against the TIC response of a standard(s). The appropriateness of the standard(s) will determine the accuracy of the method. The variability in the TIC responses of various compounds is illustrated by the work of Allgood et al. (1990). They measured the relative molar and relative weight sensitivities obtained by GC with an electronionization MS for a number of compounds having a variety of functional groups. The sensitivities for approximately 50 compounds were obtained by integrating the total-ion current (TIC) across the chromatographic peak for each compound. They showed that the sensitivity per gram varied over a range of about \pm 25 percent for many hydrocarbons and oxygenated compounds. As examples, the weight-response relative to $n$-octane was 1.15 for $n$-dodecane, 0.84 for xylene isomers, 0.96 for $n$-propylbenzene, 0.79 for hexanone, and 0.82 for diethylphthalate. The few halogenated compounds in the study generally had lower response ratios. The lowest relative responses occurred for the bromine-containing compounds, bromobenzene (0.58) and o-dibromobenzene (0.52).

Often, a fluorine- and/or bromine-containing aromatic compound, such as 1-bromo-4-fluorobenzene (BFB), is added to samples as an internal standard when analyzing these samples by GC/MS. An advantage of fluorine- and bromine-containing aromatic compounds as internal standards is that their unique spectra can not be confused with sample components. There is an additional precedent for using BFB since it is the standard for mass calibration in U.S. EPA methods. However, as illustrated above, the TIC responses for such compounds can be relatively low. In addition, MS instruments can differ in way they ionize such 
compounds. These inter-instrumental variations in ionization necessitate that response ratios of common compounds relative to a halogenated standard be measured as part of the calibration procedure.

The calibration of the GC/MS method is described in a study that measured the TVOC concentrations for samples from the Total Exposure Assessment Methodology (TEAM) studies (Wallace et al., 1991). The samples were collected on Tenax cartridges, thermally desorbed, and originally analyzed for target compounds by capillary GC/MS with the electron-ionization, quadruple MS detector scanned over a wide mass range. Prior to analysis, a known mass of perfluorobenzene was added to each sample. The stored data were retrospectively analyzed for TVOC. First, response factors relative to perfluorobenzene were determined for 17 VOCs representative of alipahatic and aromatic hydrocarbons and chlorinated compounds. The average relative TIC response factor for the 17 compounds was 0.99 with a $C V$ of 0.41 percent (single-ioncurrent response factors were found to be significantly more variable). Next, the TIC chromatogram of each sample was integrated over a retention time range delimited by chloroform and n-dodecane. The mass of TVOC in a sample was calculated from the ratio of the summed TIC area to the TIC area of perfluorobenzene and a relative response factor of unity. The uncertainty inherent in this method was estimated to be approximately 30 - 60 percent. This estimate was based on the variability in the TIC responses for the calibration compounds, an assumed variability in the TIC responses of other compounds found in indoor air, and the ability of other laboratories to reproduce the results on the same sub set of samples .

An alternative, and probably superior approach for the calibration of the GC/MS method for TVOC, is to use a single, unique, non-halogenated hydrocarbon as an internal standard (Rothweiler et al., 1992). Such compounds should ionize more similarly to the majority of compounds in typical samples of indoor air. The deuterated compounds, toluene-d8 and ethylbenzene-d $d_{10}$ can serve this purpose. They have unique mass spectra; can be chromatographically resolved from their parent compounds; and have virtually the same TIC response as the parent compounds. With one of these compounds as the internal standard, the hydrocarbon-equivalent mass of compounds comprising a sample can be calculated by assuming a relative response of unity.

The way in which chromatographic data are analyzed also has a significant impact on the results for TVOC. The retention time range over which chromatographic peaks are integrated is obviously important. In the GC/MS method described above, integration was restricted to a moderate range delimited by chloroform and $n$-dodecane. The range can be extended downward to include more volatile compounds if, for example, a multi-sorbent device is used for sample collection. Analyses of VOCs also typically include many compounds which are less volatile than dodecane. The integration thresholds and peak widths that are used to detect peaks are also critical. The most inclusive approach is to estimate the position of the baseline from the analysis of a blank and to integrate and sum all of the area above that baseline without consideration of the size or shape of the individual peaks. In practice, this may be difficult to achieve with most software programs. However, the threshold and peak-width parameters can be usually be adjusted to capture most of the area in a chromatogram. Finally, it is generally necessary to correct the summed areas by subtracting the response of appropriate blank samples regardless of the integration method.

Some investigators have taken the approach of combining methods to obtain a measure of TVOC. An example of a hybrid method is provided by Wolkoff et al. (1991) who measured concentrations of VOCs and TVOC emitted by building materials in environmental chambers. The samples were collected on Tenax; thermally desorbed; and analyzed by GC/MS. A number of compounds were individually quantified. TVOC was determined by quantifying the integrated area of the unidentified portion of a chromatogram using toluene as a standard and then adding this concentration to the sum of the concentrations of the individual compounds. Still other investigators attempt to quantify as many compounds as possible in a sample and then report the sum of the individual compounds as TVOC (e.g., Shields and Weschler, 1992). Such a method, 
in which the ten most abundant compounds in each of seven chemical classes are summed, was advocated by Siefert (1990) as a measure of TVOC.

Some of the primary issues regarding analytical considerations that are discussed in this review are illustrated in practice by the laboratory and field comparisons of three TVOC methods that are described below. The mass response of an IR gas monitor to different classes of compounds is demonstrated to vary by two orders of magnitude. An FID TVOC method is shown to quantify carbon with a high degree of accuracy while substantially underestimating the mass concentrations of chlorinated and oxidized compounds. Differences in the abilities of GC/MS systems to ionize a bromine- and fluorine-containing internal standard are confirmed. Finally, integration parameters are shown to have a significant impact on the estimation of TVOC concentrations.

\section{Comparison of Three TVOC Methods}

\section{Methods}

This investigation was undertaken to compare the FID method for TVOC reported by Hodgson et al. (1991), a GC/MS method for TVOC similar to that used by Wallace et al. (1991), and a method employing a photoacoustic IR gas monitor. The comparison was conducted in the laboratory using mixtures of compounds. In addition, the FID and GC/MS methods were used to measure TVOC concentrations in a variety of buildings with different sources of VOCs.

Samples for VOCs were actively collected on multi-sorbent tubes $(6 \mathrm{~mm}$ O.D. $\times 203 \mathrm{~mm}$ long; Part No. ST032; Envirochem, Inc., Kemblesville, PA) packed with glass beads, Tenax-TA, Ambersorb XE-340 and activated carbon, in series. For analysis, a sample was thermally desorbed at $275^{\circ} \mathrm{C}$, concentrated, and introduced into a GC with a UNACON 810A (Envirochem, Inc.) concentrating and inletting system (Hodgson and Girman, 1989). The GC was connected via a direct capillary interface to an electron-ionization, quadruple MS operated to scan a mass range of $m / z$ 33-300. A model 5970B MS with Pascal software (Hewlett-Packard Co.) was used for the analysis of laboratory samples; a model 5971A MS with DOS software (same manufacturer) was used for the analysis of field samples. The capillary column stationary phase was (14\%-cyanopropyl-phenyl)-methylpolysiloxane (Part No. 122-0733, J\&W Scientific, Folsom, $\mathrm{CA})$. The $\mathrm{GC}$ oven was ramped over a temperature range of $1-225^{\circ} \mathrm{C}$ at $5^{\circ} \mathrm{C} \mathrm{min}^{-1}$.

During the concentration step, the inletting system automatically split off about eight percent of a sample and analyzed it directly with a built-in FID. This feature allowed both an FID analysis of TVOC and a GC/MS analysis of individual VOCs to be performed on the same sample. The response of the FID was a single peak as there was no chromatographic separation of compounds. The integrated peak area was calibrated with a mixture of $\mathrm{C}_{6}-\mathrm{C}_{12}$ normal alkane hydrocarbons constituted so that each compound contributed an equal mass of carbon. The standard gas mixture was prepared in a static dilution bottle.

An internal standard consisting of known mass of BFB was added to all standards and samples. This was generated by a diffusion source or prepared in a static dilution bottle.

The TIC chromatographic responses were integrated over the entire chromatographic region spanned by 2-methylbutane and $n$-hexadecane using the MS manufacturer's software packages.

Relative response factors $\left(\mathrm{RRF}_{\mathrm{M}}\right.$ ) were determined for the 32 target VOCs in Table 2 by comparing the mass sensitivities of the TIC responses of these compounds to the mass sensitivity of the response of BFB.

Measurements of VOCs were also made with a photoacoustic IR gas monitor (Model 1302; Brüel \& Kjær, Nærum, Denmark). This instrument was equipped with an analytical filter 
(UA 0987) with a center frequency of $2950 \mathrm{~cm}^{-1}$ and a bandwidth of $180 \mathrm{~cm}^{-1}$. This was judged to be the most appropriate filter since hydrocarbons generally have infra-red absorption bands in the vicinity of $3000 \mathrm{~cm}^{-1}$ due to the $\mathrm{C}-\mathrm{H}$ stretching vibration. The instrument was calibrated for toluene over a range of $1.6-17 \mathrm{ppm}$. Measurements were automatically compensated for temperature fluctuations and for water vapor interference.

Eight different VOC mixtures were prepared for the comparison (Table 2). Five of these mixtures were composed of compounds in a single chemical class in which the concentrations of the individual compounds were approximately equal. The composition of the Common VOCs mixture was derived from a national data base of indoor VOC concentrations (Shah and Singh, 1988). The 13 compounds that had a substantial number of data points and median indoor concentrations in excess of $0.2 \mathrm{ppb}$ were selected and combined so that their percent compositions closely matched the percent compositions of their median concentrations in the data base. The Human Exposure mixture was comprised of 12 of the 22 compounds that were used to test the reactions of human subjects to indoor air pollutants (Mølhave et al., 1986). Together, these 12 compounds accounted for 97.3 percent of the mass composition of the original mixture. The ratios of their masses in the VOC mixture used here matched those of the original mixture. The Carpet Mixture is the calibration mixture of four compounds that was recommended for the GC/MS or GC/FID analysis of TVOC emitted by carpets and related products (Leukroth, 1991).

Test atmospheres were generated by injecting microliter quantities of the VOC mixtures into sealed 19-L steel chambers. Predicted concentrations expressed as the sums of the individual compounds were in the range of $38-51 \mathrm{mg} \mathrm{m}^{-3}$. Duplicate $25-\mathrm{cm}^{3}$ air samples were collected on multi-sorbent tubes from an exit manifold. Next, the air inlet to the chamber was opened, and a trap containing activated carbon was attached. The gas monitor was attached to the exit, and air was exhausted from the chamber at $2 \mathrm{~L} \mathrm{~min}^{-1}$ while the monitor continuously analyzed the exit gas stream for 30-45 min. Initial concentrations were calculated by extrapolating the exponentially decaying concentrations back to the time at the start of the analyses.

The field samples of indoor air were collected on multi-sorbent tubes from offices, residences, and a school. The sampling air flow rates were $25-250 \mathrm{~cm}^{3} \mathrm{~min}^{-1}$, and sample volumes were $1-7.5 \mathrm{~L}$. Only a single sample per building was used for this evaluation. One outdoor sample was included in the comparison. The ten buildings that are represented were impacted by a variety of typical indoor sources of VOCs. Each sample was simultaneously analyzed by the FID and GC/MS methods. The measurements were corrected for the masses of field blanks. These blanks are typically about $50 \mathrm{ng}$ of carbon by the FID method. The sampling and analysis methods for the field samples are summarized in Table 3.

\section{Results and Discussion}

The mean $R_{R F} S$ and $C V s$ for the 32 target VOCs measured by the GC/MS systems used for the laboratory and the field comparisons were $1.27 \pm 33$ percent and $1.76 \pm 40$ percent, respectively. The $\mathrm{RRF}_{\mathrm{M}}$ s were generally highest for the aliphatic and aromatic hydrocarbons compared to the other classes. The mean $\mathrm{RRF}_{\mathrm{M}} \mathrm{s}$ and $\mathrm{CVs}$ for the 13 normal alkane and aromatic hydrocarbons measured by the two systems were $1.61 \pm 26$ percent and $2.30 \pm 17$ percent, respectively. These mean values were used as the calibration factors for the laboratory and the field comparisons since the mass in indoor air samples is often dominated by hydrocarbons. Pinene and 2-propanol gave notably low responses on both GC/MS systems, and 1,1,1-trichloroethane and carbon tetrachloride gave low responses on the GC/MS system used for the field samples.

Wallace et al. (1991), using a different MS system, obtained $R_{R} F_{M S}$ for seven aliphatic and aromatic compounds and nine chlorinated compounds using perfluorobenzene as the reference standard. The mean $\mathrm{RRF}_{\mathrm{M}}$ and $\mathrm{CV}$ for this group of compounds was $0.99 \pm 41$ percent. Although the compounds were different, the $\mathrm{CV}$ was about the same as for the present study. 
Again, the hydrocarbons generally had higher sensitivities, with a mean $R_{R} F_{M}$ and $C V$ for this group of $1.25 \pm 21$ percent.

The performance of the FID TVOC method calibrated as carbon is shown in Table 4. For this evaluation, the expected concentrations of the mixtures were converted to concentrations of carbon. The concentrations measured by the FID and calculated as $\mathrm{mg}$ carbon $\mathrm{m}^{-3}$ were then compared to these values. There was good agreement between measured and expected carbon concentrations for the three hydrocarbon and the common VOCs mixtures. As anticipated, the lowest response ratio (0.68) was obtained for the mixture of oxidized compounds. The Human Exposure and Carpet Mixtures which contained oxidized compounds also produced low FID responses $(0.82)$. The mean ratio of the measured to the expected carbon concentrations for the eight mixtures was 0.93 with a $\mathrm{CV}$ of 18 percent.

Next, the FID carbon values were converted to hydrocarbon-equivalent concentrations by multiplying them by 1.15 , the average ratio of molecular weight to carbon weight for the 13 normal alkane and aromatic hydrocarbons used to calibrate the GC/MS systems. These concentrations are shown in Table 5 and are compared to the expected mass concentrations of the mixtures. Again, there was good agreement for the hydrocarbon mixtures (within \pm 17 percent). The lowest response ratios were obtained for the mixture of chlorinated compounds $(0.27)$ and the mixture of oxidized compounds (0.53). The average response ratio for the eight mixtures was 0.77 with a CV of 37 percent. Thus, these results clearly demonstrate that a FID can accurately quantify the concentration of carbon or the concentration of hydrocarbons in a sample but will substantially underestimate the mass concentration if the sample is dominated by chlorinated or oxidized compounds.

The results for the GC/MS method are also shown in Table 5. By GC/MS, the measured concentrations of the alkane and aromatic hydrocarbon mixtures were close to their expected values. This was anticipated since the method was calibrated with a mixture of these compounds. The GC/MS concentrations of all of the other mixtures were underestimated due to the lower RRF $_{M S}$ for some of the component compounds. The mean ratio of the measured to expected concentrations for the eight mixtures was 0.75 with a $\mathrm{CV}$ of 22 percent. There was generally good agreement between the FID and GC/MS methods for all mixtures, except the chlorinated hydrocarbons, when the results were expressed as hydrocarbon-equivalent concentrations

With the IR gas monitor, the ratios of the measured concentrations in $\mathrm{mg} \mathrm{m}^{-3}$ of toluene to the expected concentrations of the eight mixtures varied by two orders of magnitude (Table 5). Since the gas monitor was calibrated with toluene, accurate results were obtained for the mixture of aromatic hydrocarbons. Large discrepancies, however, were observed for the other mixtures. The instrument was most sensitive to the alkane hydrocarbons and overestimated their concentration by more than a factor of five. It was least sensitive to the chlorinated hydrocarbons for which the concentration was estimated to be only six percent of the expected value. These results demonstrate that it is inappropriate to use this instrument for measuring TVOC concentrations of gas mixtures of unknown and varying composition.

Finally, the concentrations of TVOC measured by the GC/MS and FID methods are compared for samples collected in ten buildings and an outdoor location.

The GC/MS TIC chromatograms of the field samples were first integrated in two ways. The autointegrate feature of the software, which automatically adjusts the peak width and threshold parameters, adequately integrated the major compounds in the samples but did not capture all of the minor peaks which can constitute a substantial portion of the sample mass. The selected approach was to integrate the samples using manually-set parameters (peak width $=0.4$ min; threshold $=16.5$ ) that were more inclusive and sensitive. On average, there was a 34 percent increase in sample mass. This demonstrates that the parameters used to integrate chromatograms are an important consideration in determining sample mass. 
Although the detection mechanisms were different, increased comparability between the GC/MS and FID methods was obtained by expressing the field sample results obtained by both methods as hydrocarbon-equivalent concentrations. This was achieved, as described above, by calibrating the GC/MS system with 13 normal alkane and aromatic hydrocarbons and by normalizing the FID results to the same 13 compounds.

In general, the GC/MS hydrocarbon-equivalent TVOC concentrations for the field samples were somewhat higher than the FID concentrations. On average, the difference was 17 percent with a CV of 16 percent. The GC/MS TVOC concentrations are plotted against the corresponding FID concentrations in Figure 1. The relationship is quantitatively defined by the linear regression equation $Y=-17.3+1.21 X$, where $Y$ is the GC/MS concentration and $X$ is the FID concentration $\left(r^{2}=0.977\right)$. The comparison demonstrates that the GC/MS and FID can produce highly correlated and similar results for TVOC.

\section{Conclusions}

The measurement of TVOC concentrations in indoor air is an inexact science. At present, a relatively large number of methods are used. Researchers are developing and selecting these methods based on the objectives of their studies, and on practical considerations regarding cost and the availability of sampling equipment and analytical instrumentation. Many of these methods deviate significantly making it difficult to compare results.

Despite the differences, a number of the methods for TVOC may produce results that agree within a factor of two, or better, for many typical samples of VOCs in indoor air. This review revealed that a majority of methods utilize a sorbent such as Tenax for sample collection combined with thermal desorption for sample recovery. The samples are typically analyzed by GC/FID or GC/MS with aromatic or aliphatic hydrocarbons as reference compounds. The laboratory and field comparison studies presented here demonstrated that comparable results can be achieved with a FID and a MS detector even though they operate on different principals. However, there will always be some samples, such as those dominated by chlorinated or oxidized compounds, for which both methods will probably produce inaccurate.

Uncertainties in FID and GC/MS methods for TVOC are likely to range over about 50 percent (CV) due to variations in experimental details and to differences in the compositions of VOC mixtures in buildings. These uncertainties must be kept in mind when comparing and interpreting TVOC concentrations. They also limit the usefulness of TVOC measurements. It is not a parameter that could easily be used as the basis for guidelines or regulations despite its seeming attractiveness. Realistically, TVOC is probably best used as a screening tool to determine if VOC levels in buildings are within a typical range. The frequency distribution of TVOC concentrations for a probability-based sample of 198 residences presented by Wallace et al. (1991) serves as a useful reference. The median value and geometric standard deviation for that distribution are both $0.7 \mathrm{mg} \mathrm{m}^{-3}$. TVOC measurements may also prove to be useful for assessing the potential for sub-acute health effects in indoor environments (Mølhave and Nielsen, 1992).

Until such time as standard methods are developed, researchers are reminded to fully document their methods when reporting results for TVOC since these results are strongly dependent upon the details of sample collection, analysis and data reduction. Table 3 is an example of such documentation. Complete information is needed so that others may evaluate, and, if desired, reproduce the methods to obtain comparable results.

Ultimately, more useful measures may be developed for characterizing mixtures of VOCs in buildings. In particular, measures are needed that are more directly related to potential health effects. Cometto-Muñiz and Cain (1994) have shown a relationship between nasal pungency and saturated vapor pressure for three combined classes of oxidized VOCs in which the least volatile compounds had the lowest response threshold. This suggests that it might be useful to quantify 
the distribution of mass in a sample by vapor pressure. As a first approximation, chromatograms could be divided into several retention time intervals by using selected normal alkane hydrocarbons as delimiters.

\section{Acknowledgments}

The assistance of John D. Wooley in conducting the laboratory comparison of TVOC methods is gratefully acknowledged. This project was supported by the Assistant Secretary for Energy Efficiency and Renewable Energy, Office of Building Technologies, Building Systems and Materials Division of the U.S. Department of Energy under Contract DE-AC03-76SF00098. 


\section{References}

Allgood, C., Orlando, R., and Munson, B. (1990) "Correlations of relative sensitivities in gas chromatography electron ionization mass spectrometry with molecular parameters", J. Am. Soc. Mass Spectrom., 1, 397-404.

Batterman, S. and Peng, C. (1995) "TVOC and $\mathrm{CO}_{2}$ concentrations as indicators in indoor air quality studies", Am Ind. Hyg. Assoc. J., 56, 55-65.

Brown, S.K, Sim, M.R., Abramson, M.J. and Gray, C.N. (1994) "Concentrations of volatile organic compounds in indoor air - a review", Indoor Air 4, 123-134.

Cometto-Muñiz, J.E. and Cain, W.S. (1994) "Perception of odor and nasal pungency from homologous series of volatile organic compounds", Indoor Air 4, 140-145.

De Bortoli, M., Knöppel, H., Pecchio, E., Vissers, H. (1989) "Performance of a thermally desorbable diffusion sampler for personal and indoor air monitoring", Environ. International, 15, 427-434.

Hodgson, A.T., Daisey, J.M., and Grot, R.A. (1991) "Sources and source strengths of volatile organic compounds in a new office building", J. Air Waste Manage. Assoc., 41, 14611468.

Hodgson, A.T. and Girman, J.R. (1989) "Application of a multisorbent sampling technique for investigations of volatile organic compounds in buildings". In: Nagda, N. and Harper, J. (eds), Design and Protocol for Monitoring Indoor Air Quality, ASTM STP 1002, American Society for Testing and Materials, Philadelphia, PA, pp. 244-256.

Hodgson, M., Levin, H., and Wolkoff, P. (1994) "Volatile organic compounds and indoor air", J. Allergy Clin. Immunol., 94, 296-303.

Leukroth, R.W., Jr., Ed. (1991) Carpet Policy Dialogue Compendium Report. Office of Toxic Substances, U.S. EPA, Washington, D.C., Sept. 27.

Mølhave, L., Bach, B., and Pedersen, O.F. (1986) "Human reactions to low concentrations of volatile organic compounds", Environ. International, 12, 167-175.

Mølhave, L: and Nielsen, G.D. (1992) "Interpretation and limitations of the concept 'total volatile organic compounds' (TVOC) as an indicator of human responses to exposures of volatile organic compounds (VOC) in indoor air", Indoor Air, 2, 65-77.

Rothweiler, H., Wäger, P.A., and Schlatter, C. (1992) "Volatile organic compounds and very volatile organic compounds in new and recently renovated buildings in Switzerland", Atmos. Environ., 26A, 2219-2225.

Seifert, B. (1990) "Regulating indoor air". In: Indoor Air '90, Precedings of the 5th International Conference on Indoor Air Quality and Climate, Toronto, Canada, July 29-August 3, Vol. 5, pp. 35-49.

Shah, J.J. and Singh, H.B. (1988) "Distributions of volatile organic chemicals in outdoor and indoor air, a national VOCs data base", Environ. Sci. Technol., 22, 1381-1388.

Shields, H.C. and Weschler, C.J. (1987) "Analysis of ambient concentrations of organic vapors with a passive sampler", JAPCA, 37, 1039-1045. 
Shields, H.C. and Weschler, C.J. (1992) "Volatile organic compounds measured at a telephone switching center from 5/30/85-12/6/88: A detailed case study", J. Air \& Waste Management Assoc., 42, 792-804.

Wallace, L., Pellizzari, E., and Wendel, C. (1991) "Total volatile organic concentrations in 2700 personal, indoor, and outdoor air samples collected in the US EPA Team studies", Indoor Air, 1, 465-477.

Wolkoff, P., Nielsen, G.D., Hansen, L.F., Albrechtsen, O., Johnsen, C.R., Heinig, J.H., Franck, C., and Nielsen, P.A. (1991) "A study of human reactions to emissions from building materials in climate chambers. Part II: VOC measurements, mouse bioassay, and decipol evaluation in the 1-2 mg/m³ TVOC range", Indoor Air 1, 389-403.

World Health Organization (1989) Indoor air quality: Organic pollutants. EURO Reports and Studies No. 111, Copenhagen, Denmark.

Yieru, H., Qingyu, O., and Weile, Y. (1990) "Characteristics of flame ionization detection for the quantitative analysis of complex organic mixtures", Anal. Chem., 62, 2063-2064. 
Table 1 Categorization of TVOC methods reported at Indoor Air '93, The Sixth International Symposium on Indoor Air Quality and Climate, Helsinki, Finland, June, 1993.

\begin{tabular}{lclc}
\hline Method & $\begin{array}{c}\text { No. } \\
\text { Reported }\end{array}$ & Method & $\begin{array}{c}\text { No. } \\
\text { Reported }\end{array}$ \\
\hline $\begin{array}{l}\text { Sampling } \\
\text { Active sampling }\end{array}$ & 21 & Analysis & \\
Diffusive sampling & 3 & GC/MS & 7 \\
Direct measurement & 3 & GC/FID & 16 \\
& & FID without GC & 1 \\
Collection Media & 11 & Direct on-site FID & 1 \\
Tenax/Thermal & 5 & Direct on-site IR & 2 \\
Other sorbent/Thermal & 6 & Reference Compound & \\
Charcoal/Solvent extract & & Toluene & 8 \\
& & Alkane HC & 6 \\
& & Compound mixture & 2 \\
\hline
\end{tabular}


Table 2 Compositions of eight VOC mixtures used for the comparison of three TVOC methods.

\begin{tabular}{|c|c|c|c|}
\hline Compound & $\begin{array}{c}\text { Conc. } \\
\mathrm{mg} \mathrm{m}^{-3}\end{array}$ & Compound & $\begin{array}{l}\text { Conc. } \\
\mathrm{mg} \mathrm{m}^{-3}\end{array}$ \\
\hline Alkane HCs & & Common VOCs & \\
\hline n-Hexane & 5.4 & n-Octane & 1.8 \\
\hline n-Heptane & 5.5 & n-Nonane & 2.8 \\
\hline n-Octane & 5.4 & n-Decane & 1.2 \\
\hline n-Nonane & 5.5 & n-Undecane & 1.4 \\
\hline n-Decane & 5.3 & Benzene & 7.4 \\
\hline n-Undecane & 5.4 & Toluene & 4.8 \\
\hline \multirow[t]{2}{*}{ n-Dodecane } & 5.5 & Dimethylbenzenes & 13.6 \\
\hline & & Styrene & 0.9 \\
\hline Aromatic HCs & & Trimethylbenzenes & 2.0 \\
\hline Benzene & 8.0 & $\alpha$-Pinene & 0.8 \\
\hline Toluene & 7.9 & $1,1,1$-Trichloroethane & 7.8 \\
\hline Ethylbenzene & 7.9 & Tetrachloroethene & 3.7 \\
\hline 1,2-Dimethylbenzene & 8.0 & Dichlorobenzenes & 2.5 \\
\hline Styrene & 7.8 & & \\
\hline \multirow[t]{2}{*}{$1,2,3$-Trimethylbenzene } & 7.7 & Human Exposure & \\
\hline & & n-Hexane & 1.6 \\
\hline Misc. HCs & & n-Nonane & 1.5 \\
\hline Cyclohexane & 6.9 & n-Decane & 1.5 \\
\hline Methylcyclohexane & 6.9 & Ethylbenzene & 1.5 \\
\hline 1-Octene & 7.1 & Dimethylbenzene & 15.3 \\
\hline$\alpha$-Pinene & 6.8 & $\alpha$-Pinene & 1.5 \\
\hline 1-Decene & 7.0 & 1-Decene & 1.5 \\
\hline \multirow[t]{2}{*}{ Limonene } & 7.1 & 1,2-Dichloroethane & 1.5 \\
\hline & & 1-Butanol & 1.4 \\
\hline Chlorinated HCs & & Butyl acetate & 15.6 \\
\hline Dichloromethane & 6.4 & Hexanal & 1.4 \\
\hline 1,1,1-Trichloroethane & 6.4 & 2-Ethoxyethyl acetate & 1.4 \\
\hline Carbon tetrachloride & 6.5 & & \\
\hline Trichloroethene & 6.4 & Carpet Mixture & \\
\hline Tetrachloroethene & 6.3 & n-Decane & 10.5 \\
\hline \multirow[t]{2}{*}{ 1,2-Dichlorobenzene } & 6.3 & Toluene & 10.7 \\
\hline & & Cyclohexane & 10.4 \\
\hline Oxidized Compounds & & 1-Hexanol & 10.4 \\
\hline 2-Propanone & 6.4 & & \\
\hline 2-Butanone & 6.5 & & \\
\hline 2-Propanol & 6.3 & & \\
\hline Butyl acetate & 6.4 & & \\
\hline Hexanal & 6.5 & & \\
\hline 1-Hexanol & 6.5 & & \\
\hline Benzaldehyde & 6.3 & & \\
\hline
\end{tabular}


Table 3 Summary of sampling and analysis procedures and instrumentation for the GC/MS and FID methods used to measure TVOC in field samples.

\begin{tabular}{|c|c|c|}
\hline Parameter & GC/MS Method & FID Method \\
\hline $\begin{array}{l}\text { Sample-collection } \\
\text { media }\end{array}$ & $\begin{array}{l}\text { Multi-sorbent tubes; No. ST032, } \\
\text { Envirochem }\end{array}$ & Same \\
\hline Sample volumes & Typically $2-3 \mathrm{~L}$ & Same \\
\hline $\begin{array}{l}\text { Sample-recovery } \\
\text { technique }\end{array}$ & $\begin{array}{l}\text { Thermal desorption; UNACON } \\
\text { 810, Envirochem }\end{array}$ & Same \\
\hline Fraction analyzed & 92 Percent & 8 Percent \\
\hline GC column & No. 122-0733, J\&W Scientific & Not applicable \\
\hline GC oven program & $1-225^{\circ} \mathrm{C}, 5^{\circ} \mathrm{C} \mathrm{min}-1$ & Not applicable \\
\hline Detector & $\begin{array}{l}\text { MS; Model 5971A with DOS } \\
\text { software, Hewlett-Packard }\end{array}$ & FID; Model 782, Envirochem \\
\hline Mass scan range & $m / z 33-300$ & Not applicable \\
\hline Integration technique & $\begin{array}{l}\text { Peak width =0.4 min; threshold } \\
\quad=16.5\end{array}$ & $\begin{array}{l}\text { Single peak; Model 3396A } \\
\text { integrator, Hewlett-Packard }\end{array}$ \\
\hline $\begin{array}{l}\text { Compound volatility } \\
\text { range }\end{array}$ & 2-Metylbutane - $\mathrm{n}$-hexadecane & Same \\
\hline $\begin{array}{l}\text { Calibration } \\
\text { compound(s) }\end{array}$ & $\begin{array}{l}\text { Mixture of } 13 \text { alkane \& aromatic } \\
\mathrm{HCs}\end{array}$ & Mixture of $\mathrm{C}_{6}-\mathrm{C}_{12}$ alkane $\mathrm{HCs}$ \\
\hline $\begin{array}{l}\text { Calibration } \\
\text { procedure }\end{array}$ & $\begin{array}{l}\text { Response relative to } \mathrm{BFB} \\
\text { internal standard }\end{array}$ & $\begin{array}{l}\text { Multipoint external standard } \\
\text { calibration }\end{array}$ \\
\hline Blank correction & System or field blanks & Same \\
\hline
\end{tabular}


Table 4 TVOC carbon concentrations measured by the FID method compared to the expected carbon concentrations of eight VOC mixtures.

\begin{tabular}{|c|c|c|c|c|}
\hline \multirow[b]{2}{*}{ Mixture } & \multirow{2}{*}{$\begin{array}{c}\text { No. } \\
\text { Cmpds. }\end{array}$} & \multicolumn{2}{|c|}{ Concentration, $\mathrm{mg} \mathrm{C} \mathrm{m}^{-3}$} & \multirow{2}{*}{$\begin{array}{c}\text { Meas/ } \\
\text { Expected }\end{array}$} \\
\hline & & Expected & Measured & \\
\hline Alkane $\mathrm{HCs}$ & 7 & 32.0 & 34.8 & 1.09 \\
\hline Aromatic HCs & 6 & 43.0 & 48.0 & 1.12 \\
\hline Misc. HCs & 6 & 36.1 & 31.5 & 0.87 \\
\hline Chlorinated HCs & 6 & 7.79 & 8.95 & 1.15 \\
\hline Oxidized Cmpds. & 7 & 30.3 & 20.6 & 0.68 \\
\hline Common VOCs & 13 & 36.1 & 33.2 & 0.92 \\
\hline Human Exposure & 12 & 35.3 & 28.9 & 0.82 \\
\hline \multirow[t]{2}{*}{ Carpet Mixture } & 4 & 35.2 & 29.0 & 0.82 \\
\hline & & & $\begin{array}{l}\text { Mean } \\
\text { CV,\% }\end{array}$ & $\begin{array}{l}0.93 \\
18\end{array}$ \\
\hline
\end{tabular}


Table 5 TVOC mass concentrations measured by the GC/MS and FID methods and tolueneequivalent concentrations measured by an IR gas monitor for eight VOC mixtures. Numbers of compounds in each mixture are shown in parentheses.

\begin{tabular}{|c|c|c|c|c|c|c|c|}
\hline \multirow[b]{2}{*}{ Mixture } & \multirow[b]{2}{*}{$\begin{array}{c}\text { Expect } \\
\text { Conc } \\
\mathrm{mg} \mathrm{m}^{-3}\end{array}$} & \multicolumn{2}{|c|}{ GC/MS } & \multicolumn{2}{|c|}{ FID } & \multicolumn{2}{|c|}{ IR Gas Monitor } \\
\hline & & $\begin{array}{c}\text { Measured } \\
\text { Conc } \\
\mathrm{mg} \mathrm{m}^{-3}\end{array}$ & $\begin{array}{l}\text { Meas/ } \\
\text { Expect } \\
\text { Ratio }\end{array}$ & $\begin{array}{l}\text { Measured } \\
\text { Conc } \\
\mathrm{mg} \mathrm{m}^{-3}\end{array}$ & $\begin{array}{c}\text { Meas/ } \\
\text { Expect } \\
\text { Ratio }\end{array}$ & $\begin{array}{l}\text { Toluene } \\
\text { Conc } \\
\mathrm{mg} \mathrm{m}^{-3}\end{array}$ & $\begin{array}{l}\text { Meas/ } \\
\text { Expect } \\
\text { Ratio }\end{array}$ \\
\hline Alkane HCs (7) & 38.0 & 41.5 & 1.09 & 40.0 & 1.05 & 211 & 5.56 \\
\hline Aromatic HCs (6) & 47.2 & 41.5 & 0.88 & 55.2 & 1.17 & 53.0 & 1.12 \\
\hline Misc. HCs (6) & 41.7 & 28.8 & 0.69 & 36.2 & 0.87 & 204 & 4.89 \\
\hline Chlorinated HCs (6) & 38.3 & 25.9 & 0.68 & 10.3 & 0.27 & 2.4 & 0.06 \\
\hline Oxidized Cmpds. (7) & 44.9 & 26.0 & 0.58 & 23.7 & 0.53 & 100 & 2.23 \\
\hline Common VOCs (13) & 50.6 & 33.7 & 0.67 & 38.2 & 0.76 & 70.8 & 1.40 \\
\hline Human Exposure (12) & 45.7 & 30.5 & 0.67 & 33.2 & 0.73 & 122 & 2.66 \\
\hline \multirow[t]{3}{*}{ Carpet Mixture (4) } & 42.5 & 31.0 & 0.73 & 33.4 & 0.79 & 192 & 4.53 \\
\hline & & Mean & 0.75 & & 0.77 & & 2.81 \\
\hline & & & & & & & \\
\hline
\end{tabular}




\section{Figure Caption}

Fig: 1 GC/MS versus FID hydrocarbon-equivalent TVOC concentrations for one outdoor and ten indoor air samples.

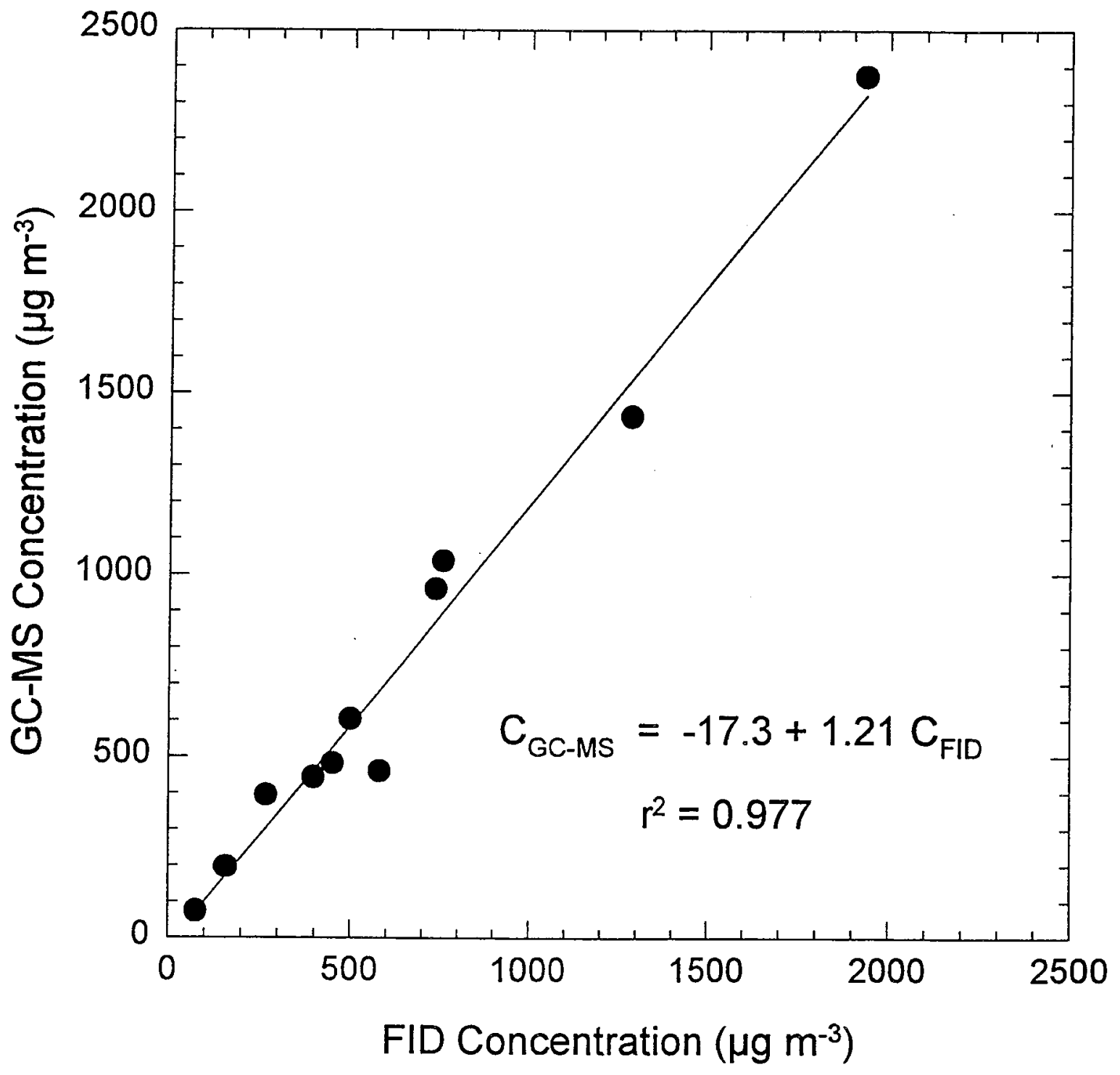

